\title{
Effect of azilsartan versus candesartan on morning blood pressure surges in Japanese patients with essential hypertension
}

\author{
Hiromi Rakugi $^{\mathrm{a}}$, Kazuomi Kario ${ }^{\mathrm{c}}$, Kazuaki Enya ${ }^{\mathrm{b}}$, Kenkichi Sugiura ${ }^{\mathrm{b}}$ \\ and Yoshinori lkeda
}

\begin{abstract}
Morning blood pressure (BP) surge is reported as a risk factor for cardiovascular events and end-organ damage independent of the 24-h BP level. Controlling morning BP surge is therefore important to help prevent onset of cardiovascular disease. We compared the efficacy of azilsartan and candesartan in controlling morning systolic BP (SBP) surges by analyzing relevant ambulatory BP monitoring data in patients with/without baseline BP surges. As part of a 16-week randomized, double-blind study of azilsartan (20-40 mg once daily) and candesartan (8-12 mg once daily) in Japanese patients with essential hypertension, an exploratory analysis was carried out using ambulatory BP monitoring at baseline and week 14. The effects of study drugs on morning BP surges, including sleep trough surge (early morning SBP minus the lowest night-time SBP) and prewaking surge (early morning SBP minus SBP before awakening), were evaluated. Patients with sleep trough surge of at least $35 \mathrm{mmHg}$ were defined by the presence of a morning BP surge (the 'surge group'). Sleep trough surge and prewaking surge data were available at both baseline and week 14 in 548 patients, 147 of whom (azilsartan 76; candesartan 71) had a baseline morning BP surge. In surge group patients, azilsartan significantly reduced both the sleep trough
\end{abstract}

\section{Introduction}

Cardiovascular events such as acute myocardial infarction and stroke occur frequently in the period from early morning to noon [1-6]. Early morning blood pressure (BP) elevation/hypertension is significantly related to an increased risk to organs such as the brain, heart, and kidney [7,8], and it is therefore very important to manage early morning hypertension to help prevent the onset of cardiovascular events.

Two types of early morning hypertension have been reported: one that transitions from night-time hypertension (nondipper) and the other where BP increases markedly in the early morning (surge). Both types are reported to be risks for cardiovascular disease [9]. Although a moderate morning surge in BP is a normal physiological phenomenon, a marked BP surge is a risk factor for cardiovascular events

This is an open-access article distributed under the terms of the Creative Commons Attribution-NonCommercial-NoDerivatives 3.0 License, where it is permissible to download and share the work provided it is properly cited. The work cannot be changed in any way or used commercially. surge and the prewaking surge at week 14 compared with candesartan (least squares means of the betweengroup differences $-5.8 \mathrm{mmHg}, P=0.0395$; and $-5.7 \mathrm{mmHg}, P=0.0228$, respectively). Once-daily azilsartan improved sleep trough surge and prewaking surge to a greater extent than candesartan in Japanese patients with grade I-II essential hypertension. Blood Press Monit 19:164-169 (c) 2014 Wolters Kluwer Health | Lippincott Williams \& Wilkins.

Blood Pressure Monitoring 2014, 19:164-169

Keywords: azilsartan, candesartan, hypertension, morning blood pressure surge

aDepartment of Geriatric Medicine and Nephrology, Osaka University Graduate School of Medicine, ${ }^{\text {b}}$ Drug Development Division, Pharmaceutical Development Division, Takeda Pharmaceutical Company Limited, Osaka and 'Department of Medicine, Division of Cardiovascular Medicine, Jichi Medical University School of Medicine, Tochigi-ken, Japan

Correspondence to Hiromi Rakugi, MD, Department of Geriatric Medicine and Nephrology, Osaka University Graduate School of Medicine, 2-2 Yamadaoka, B6, Suita, Osaka 565-0871, Japan

Tel: +8166879 3852; fax: +8166879 3859;

e-mail: rakugi@geriat.med.osaka-u.ac.jp

Received 3 December 2013 Revised 21 February 2014 Accepted 28 February 2014

and end-organ damage independent of the 24-h BP level [10-19]. For example, in the recent IDACO (International Database on Ambulatory Blood Pressure Monitoring in Relation to Cardiovascular Outcomes) study, a meta-analysis of cohort studies using ambulatory blood pressure monitoring (ABPM), it was found that morning $\mathrm{BP}$ surge was a risk factor for cardiovascular events independent of both the 24-h BP level and the fall of BP during the night (night-time BP/daytime BP) [20]. Similarly, the JMSABPM study (Wave 1 ) reported that morning BP surge is a risk factor for strokes independent of the 24-h BP level and that a morning systolic BP (SBP) surge of $10 \mathrm{mmHg}$ increases the risk of stroke by $22 \%$ [10,21]. Therefore, controlling morning BP surge is important to prevent the onset of cardiovascular disease. However, few antihypertensive agents administered once daily are capable of maintaining a BP-lowering effect over a full 24-h period. Thus, the following morning, when the antihypertensive effects begin to wear off, BP variations from the previous night may not be corrected; thus, early morning BP surges and hypertension may occur.

DOI: 10.1097/MBP.0000000000000042 
Azilsartan is a new angiotensin II receptor blocker (ARB) that is expected to exert a more potent and sustained BPlowering effect compared with existing ARBs because of its receptor binding properties. In-vitro studies have shown that azilsartan exerts a more potent inhibitory effect on angiotensin II type $1\left(\mathrm{AT}_{1}\right)$ receptors and dissociates more slowly from the receptor than other currently marketed ARBs, including olmesartan, telmisartan, valsartan, and irbesartan [22]. In a recent randomized, double-blind, comparative study in Japanese patients with stage I-II essential hypertension, azilsartan was found to have safety and tolerability similar to that of candesartan, but it showed superior antihypertensive efficacy. In addition, ABPM data indicated that azilsartan had a more sustained BP-lowering effect than candesartan, and was effective for a full 24-h period [23]. Moreover, a follow-up analysis from the randomized, double-blind, comparative study showed the efficacy of azilsartan against changes in night-time BP [24].

In this exploratory analysis, we evaluated the efficacy of azilsartan relative to that of candesartan in controlling morning SBP surges by analyzing relevant ABPM data in patients with and without baseline BP surges.

\section{Methods}

In the previous study, azilsartan was compared with candesartan in Japanese patients over a period of 16 weeks at 33 centers in Japan between May 2009 and June 2010 (clinical trial identifier: JapicCTI-090762) [23]. The study procedures, patient inclusion/exclusion criteria, dosage regimens, efficacy and safety endpoints, statistical analyses, and ethical provisions have been reported in detail previously [23], and will be described only briefly here. Patients received either azilsartan $20 \mathrm{mg}$ daily for the first 8 weeks, followed by $40 \mathrm{mg}$ daily for the second 8 weeks, or candesartan cilexetil (candesartan) $8 \mathrm{mg}$ daily for the first 8 weeks, followed by $12 \mathrm{mg}$ daily for the second 8 weeks. At baseline (week 0) and subsequently at week 14 , ABPM was performed over a period of $26 \mathrm{~h}$ or higher, during which time BP was measured at 30-min intervals starting at 10:00 h $( \pm 1 \mathrm{~h})$; full details of the ABPM method have been described in the previous report [23].

\section{Analysis of morning BP surge by ABPM}

Patients who underwent ABPM at baseline were classified as having a sleep trough surge (defined using criteria similar to those of the IDACO study [20]) or no sleep trough surge. The following definitions were applied: early morning SBP was defined as the mean SBP measured during the 2-h period after awakening. SBP before awakening was defined as the mean SBP measured during the 2-h period before awakening. Lowest night-time SBP was defined as the mean SBP measured during the period $35 \mathrm{~min}$ before and after measurement of the lowest sleep SBP. Sleep trough surge was defined as an increase in SBP from the lowest nighttime SBP to the early morning SBP, whereas prewaking surge was defined as the early morning SBP minus the SBP before awakening. The presence of a morning BP surge was defined as a sleep trough surge of at least $35 \mathrm{mmHg}$.

\section{Statistical analysis}

Differences between azilsartan and candesartan in controlling morning BP surges were analyzed by comparing the mean $( \pm S D)$ decreases from baseline in sleep trough surge and prewaking surge recorded in the two treatment groups. Least squares means and two-sided $95 \%$ confidence intervals (CIs) for the differences between the two groups (azilsartan minus candesartan) were calculated using an analysis of covariance model with a two-sided significance level of $5 \%$, with the plasma renin activity $(<0.5$ or $\geq 0.5 \mathrm{ng} / \mathrm{ml} / \mathrm{h}$ ) at week 2 and treatment group as independent variables, and baseline values as a covariate. Differences with $P$ value less than 0.05 were considered to be significant.

\section{Results \\ Patient characteristics}

Overall, 636 patients were randomized to treatment and both baseline and week 14 ABPM data were available for 548 patients; 273 received azilsartan and 275 received candesartan. A morning BP surge was experienced by 147 patients (azilsartan 76; candesartan 71) at baseline (the 'surge group'), whereas 401 patients did not experience a morning BP surge (azilsartan 197; candesartan 204) at baseline (the 'nonsurge group'). The proportions of patients classified as surge/nonsurge were similar in the two treatment groups. The demographic and clinical characteristics of the two treatment groups according to surge status are shown in Table 1. In the azilsartan group, more women than men had a sleep trough surge (55.3 vs. $44.7 \%)$, whereas the converse was true in the candesartan group (45.1 vs. $54.9 \%$ ). In all other respects, there were no remarkable differences in the characteristics of patients with and without surges.

\section{Changes in ABPM parameters in patients with a morning BP surge}

The mean $( \pm \mathrm{SD})$ changes in SBP from baseline to week 14 in the 24-h mean, daytime, night-time, lowest nighttime, early morning, and BP before awakening for patients with a morning BP surge at baseline are shown in Table 2. These ABPM parameters were significantly reduced at week 14 from baseline in patients treated with both azilsartan $(P<0.0001)$ and candesartan $(P<0.001)$ in the surge group. Furthermore, the reductions were significantly greater with azilsartan than with candesartan for each ABPM parameter (Table 2). Notable differences between azilsartan and candesartan in the surge group were observed in the 24-h mean SBP, mean daytime SBP, lowest night-time SBP, and early morning SBP. Changes in these parameters in the two groups were as follows: -15.1 versus $-10.0 \mathrm{mmHg}(P=0.0103),-16.1$ versus $-9.9 \mathrm{mmHg}$ 
Table 1 Baseline (week 0) demographic and clinical characteristics in patients in whom the morning BP surge status could be determined by ABPM

\begin{tabular}{|c|c|c|c|c|}
\hline \multirow[b]{2}{*}{ Characteristics } & \multicolumn{2}{|c|}{ Azilsartan } & \multicolumn{2}{|c|}{ Candesartan } \\
\hline & Surge $(n=76)$ & Nonsurge $(n=197)$ & Surge $(n=71)$ & Nonsurge $(n=204)$ \\
\hline Age & $57.4 \pm 9.57$ & $56.7 \pm 9.50$ & $58.5 \pm 9.96$ & $56.4 \pm 9.95$ \\
\hline \multicolumn{5}{|l|}{ Sex } \\
\hline Male & $34(44.7)$ & $126(64.0)$ & $39(54.9)$ & $131(64.2)$ \\
\hline Female & $42(55.3)$ & $71(36.0)$ & $32(45.1)$ & $73(35.8)$ \\
\hline BMI $\left(\mathrm{kg} / \mathrm{m}^{2}\right)$ & $25.28 \pm 4.14$ & $25.69 \pm 4.22$ & $25.45 \pm 3.91$ & $25.30 \pm 3.76$ \\
\hline Duration of hypertension (years) & $9.06 \pm 8.06$ & $8.38 \pm 7.97$ & $7.56 \pm 6.98$ & $7.78 \pm 7.22$ \\
\hline \multicolumn{5}{|l|}{ Sitting BP $(\mathrm{mmHg})$} \\
\hline SBP & $159.7 \pm 7.64$ & $159.9 \pm 7.86$ & $158.9 \pm 6.80$ & $159.5 \pm 7.07$ \\
\hline DBP & $99.7 \pm 3.81$ & $100.5 \pm 4.38$ & $99.8 \pm 3.85$ & $100.5 \pm 4.19$ \\
\hline Pulse (bpm) & $69.9 \pm 8.96$ & $70.9 \pm 9.02$ & $69.5 \pm 8.32$ & $68.7 \pm 8.34$ \\
\hline \multicolumn{5}{|l|}{ ABPM $(\mathrm{mmHg})$} \\
\hline \multicolumn{5}{|l|}{ (a) SBP } \\
\hline 24-h mean BP & $153.8 \pm 12.30$ & $154.7 \pm 14.05$ & $153.8 \pm 11.74$ & $154.7 \pm 14.16$ \\
\hline Daytime mean BP (waking state) & $162.5 \pm 13.64$ & $159.0 \pm 13.67$ & $161.8 \pm 12.27$ & $158.8 \pm 14.29$ \\
\hline Night-time mean BP (sleeping state) & $135.7 \pm 13.26$ & $145.6 \pm 17.46$ & $136.7 \pm 15.53$ & $145.9 \pm 16.70$ \\
\hline Lowest night-time BP & $122.6 \pm 14.53$ & $137.9 \pm 17.34$ & $122.4 \pm 14.26$ & $137.7 \pm 16.47$ \\
\hline Early morning mean BP & $167.3 \pm 14.19$ & $157.3 \pm 16.03$ & $166.8 \pm 13.48$ & $156.3 \pm 14.95$ \\
\hline BP before awakening & $140.5 \pm 15.48$ & $146.6 \pm 18.87$ & $140.9 \pm 14.76$ & $147.1 \pm 16.78$ \\
\hline Sleep trough surge (early morning BP-lowest night-time BP) & $44.7 \pm 9.92$ & $19.5 \pm 10.19$ & $44.4 \pm 9.17$ & $18.6 \pm 10.56$ \\
\hline Prewaking surge (early morning BP - BP before awakening) & $26.8 \pm 13.13$ & $10.7 \pm 12.08$ & $26.0 \pm 11.74$ & $9.2 \pm 11.45$ \\
\hline Nocturnal SBP fall (\%) & $16.3 \pm 6.47$ & $8.4 \pm 7.61$ & $15.4 \pm 6.65$ & $8.1 \pm 7.60$ \\
\hline \multicolumn{5}{|l|}{ (b) DBP } \\
\hline 24-h mean BP & $93.8 \pm 8.67$ & $94.5 \pm 10.02$ & $92.9 \pm 8.55$ & $94.9 \pm 9.81$ \\
\hline Daytime mean BP (in waking state) & $99.4 \pm 9.99$ & $97.7 \pm 10.31$ & $97.8 \pm 8.75$ & $97.9 \pm 10.13$ \\
\hline Night-time mean BP (sleeping state) & $82.5 \pm 8.59$ & $87.5 \pm 11.14$ & $82.1 \pm 9.48$ & $88.6 \pm 10.47$ \\
\hline BP before awakening & $86.0 \pm 9.82$ & $88.9 \pm 12.01$ & $86.1 \pm 11.70$ & $90.2 \pm 11.58$ \\
\hline Prewaking surge (early morning BP - BP before awakening) & $16.3 \pm 9.40$ & $8.9 \pm 9.77$ & $15.9 \pm 10.17$ & $8.1 \pm 9.56$ \\
\hline Plasma renin activity $(\mathrm{ng} / \mathrm{ml} / \mathrm{h})$ & $0.63 \pm 0.67$ & $0.63 \pm 0.50$ & $0.72 \pm 0.91$ & $0.58 \pm 0.47$ \\
\hline eGFR $\left(\mathrm{ml} / \mathrm{min} / 1.73 \mathrm{~m}^{2}\right)$ & $80.01 \pm 13.82$ & $75.76 \pm 13.96$ & $77.10 \pm 16.82$ & $76.45 \pm 13.94$ \\
\hline \multicolumn{5}{|l|}{ Pretreatment antihypertensives } \\
\hline Yes & $60(78.9)$ & $149(75.6)$ & $53(74.6)$ & $150(73.5)$ \\
\hline No & $16(21.1)$ & $48(24.4)$ & $18(25.4)$ & $54(26.5)$ \\
\hline \multicolumn{5}{|l|}{ Concurrent disease (diabetes) } \\
\hline Yes & $17(22.4)$ & $36(18.3)$ & $13(18.3)$ & $49(24.0)$ \\
\hline No & $59(77.6)$ & $161(81.7)$ & $58(81.7)$ & $155(76.0)$ \\
\hline \multicolumn{5}{|l|}{ Concurrent disease (hyperlipidemia) } \\
\hline Yes & $45(59.2)$ & $118(59.9)$ & $39(54.9)$ & $111(54.4)$ \\
\hline No & $31(40.8)$ & $79(40.1)$ & $32(45.1)$ & $93(45.6)$ \\
\hline
\end{tabular}

Values are means $\pm S D$ or numbers of patients (\%) (sex, pretreatment antihypertensives, and concurrent disease).

ABPM, ambulatory BP monitoring; BP, blood pressure; DBP, diastolic blood pressure; eGFR, estimated glomerular filtration rate; SBP, systolic blood pressure.

$(P=0.0071),-11.9$ versus $-6.7 \mathrm{mmHg}(P=0.0236)$, and -21.3 versus $-11.1 \mathrm{mmHg}(P=0.0002)$, respectively.

\section{Changes in sleep trough surge and prewaking surge in patients with a morning BP surge}

In patients with a morning BP surge at baseline, the mean $( \pm S D)$ changes in the sleep trough surge (i.e. early morning SBP minus lowest night-time SBP) and prewaking surge (i.e. early morning SBP minus SBP before awakening) from baseline to week 14 in the two treatment groups are shown in Table 2. For both surge types, the mean changes at week 14 with azilsartan were significantly greater than those with candesartan (sleep trough surge: -9.3 vs. $-4.4 \mathrm{mmHg}$, respectively; $P=0.0395$; prewaking surge: -5.7 vs. $+0.1 \mathrm{mmHg}$, respectively; $P=0.0228$ ) (Fig. 1 ).

\section{Changes in ABPM parameters and BP surges in patients without a morning $B P$ surge}

In patients without a morning $\mathrm{BP}$ surge at baseline, the mean SBP changes for 24-h mean, daytime, night-time, lowest night-time, and early morning and BP before awakening were significantly reduced at week 14 from baseline in patients treated with either azilsartan or candesartan $(P<0.0001$, respectively). The reductions were also significantly greater with azilsartan than with candesartan for the 24-h mean SBP $(-12.2$ vs. $-9.1 \mathrm{mmHg} ; P=0.0114)$ and the mean daytime SBP ( -10.6 vs. $-6.8 \mathrm{mmHg} ; P=0.0038)$. Although the mean changes in SBP in night-time, lowest night-time, and early morning and $\mathrm{BP}$ before awakening were slightly greater with azilsartan than with candesartan, the differences between the two treatment groups were not statistically significant (Table 2).

The sleep trough surges and prewaking surges were increased in both treatment groups $(8.3$ and $4.9 \mathrm{mmHg}$ with azilsartan, 9.1 and $6.7 \mathrm{mmHg}$ with candesartan). The results for azilsartan and candesartan with respect to surges in nonsurge patients showed similar trends.

\section{Discussion}

The efficacy of antihypertensive therapy in suppressing morning BP surges has been reported for some drugs, 
Table 2 Magnitude of changes in SBP from baseline to week 14 in patients receiving azilsartan and candesartan according to their baseline morning BP surge status

\begin{tabular}{|c|c|c|c|c|c|c|}
\hline \multirow[b]{2}{*}{ Variables } & \multicolumn{2}{|c|}{ Azilsartan } & \multicolumn{2}{|c|}{ Candesartan } & \multirow[b]{2}{*}{ LS mean $(95 \% \mathrm{Cl})^{\mathrm{a}}($ Azil - Cand $)$} & \multirow[b]{2}{*}{$P$ value (Azil vs. Cand) } \\
\hline & Number of patients & Magnitude of change & Number of patients & Magnitude of change & & \\
\hline \multicolumn{7}{|c|}{ 24-h mean BP (mmHg) } \\
\hline Surge & 76 & $-15.1 \pm 18.00$ & 71 & $-10.0 \pm 12.59$ & $-6.3(-11.16,-1.52)$ & 0.0103 \\
\hline Nonsurge & 197 & $-12.2 \pm 12.54$ & 204 & $-9.1 \pm 11.07$ & $-2.8(-4.99,-0.64)$ & 0.0114 \\
\hline \multicolumn{7}{|c|}{ Daytime mean BP (mmHg) } \\
\hline Surge & 76 & $-16.1 \pm 20.02$ & 71 & $-9.9 \pm 13.79$ & $-7.3(-12.66,-2.03)$ & 0.0071 \\
\hline Nonsurge & 197 & $-10.6 \pm 13.14$ & 204 & $-6.8 \pm 12.20$ & $-3.5(-5.79,-1.12)$ & 0.0038 \\
\hline \multicolumn{7}{|c|}{ Night-time mean BP (mmHg) } \\
\hline Surge & 76 & $-14.0 \pm 17.05$ & 71 & $-10.3 \pm 13.91$ & $-5.0(-9.81,-0.21)$ & 0.0407 \\
\hline Nonsurge & 197 & $-15.8 \pm 15.95$ & 204 & $-13.3 \pm 13.33$ & $-2.3(-4.91,0.39)$ & 0.0951 \\
\hline \multicolumn{7}{|c|}{ Lowest night-time $\mathrm{BP}(\mathrm{mmHg})$} \\
\hline Surge & 76 & $-11.9 \pm 18.33$ & 71 & $-6.7 \pm 14.45$ & $-5.9(-10.96,-0.80)$ & 0.0236 \\
\hline Nonsurge & 197 & $-17.0 \pm 18.47$ & 204 & $-15.2 \pm 16.00$ & $-1.4(-4.54,1.66)$ & 0.3618 \\
\hline \multicolumn{7}{|c|}{ Early morning mean $\mathrm{BP}(\mathrm{mmHg})$} \\
\hline Surge & 76 & $-21.3 \pm 23.67$ & 71 & $-11.1 \pm 16.35$ & $-11.7(-17.90,-5.56)$ & 0.0002 \\
\hline Nonsurge & 197 & $-8.7 \pm 18.71$ & 204 & $-6.1 \pm 15.50$ & $-2.0(-5.26,1.16)$ & 0.2106 \\
\hline \multicolumn{7}{|c|}{ BP before awakening $(\mathrm{mmHg})$} \\
\hline Surge & 76 & $-15.6 \pm 21.31$ & 71 & $-11.2 \pm 16.99$ & $-5.7(-11.20,-0.13)$ & 0.0451 \\
\hline Nonsurge & 197 & $-13.6 \pm 17.71$ & 204 & $-12.8 \pm 14.92$ & $-0.7(-3.71,2.23)$ & 0.6248 \\
\hline \multicolumn{7}{|c|}{ Sleep trough surge $(\mathrm{mmHg})^{b}$} \\
\hline Surge & 76 & $-9.3 \pm 19.64$ & 71 & $-4.4 \pm 15.18$ & $-5.8(-11.34,-0.28)$ & 0.0395 \\
\hline Nonsurge & 197 & $8.3 \pm 17.96$ & 204 & $9.1 \pm 16.15$ & $-0.3(-3.41,2.74)$ & 0.8303 \\
\hline \multicolumn{7}{|c|}{ Prewaking surge $(\mathrm{mmHg})^{\mathrm{C}}$} \\
\hline Surge & 76 & $-5.7 \pm 18.78$ & 71 & $0.1 \pm 15.98$ & $-5.7(-10.68,-0.81)$ & 0.0228 \\
\hline Nonsurge & 197 & $4.9 \pm 17.37$ & 204 & $6.7 \pm 15.36$ & $-0.7(-3.35,1.99)$ & 0.6148 \\
\hline
\end{tabular}

Values are means $\pm S D$.

ANCOVA, analysis of covariance; Azil, azilsartan; BP, blood pressure; Cand, candesartan; Cl, confidence interval; LS, least squares; SBP, systolic blood pressure.

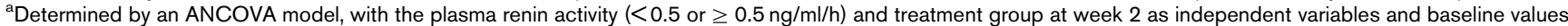
as a covariate.

bSleep trough surge = mean early morning BP minus lowest night-time BP.

${ }^{\mathrm{c}}$ Prewaking surge $=$ mean early morning BP minus BP before awakening.

Fig. 1

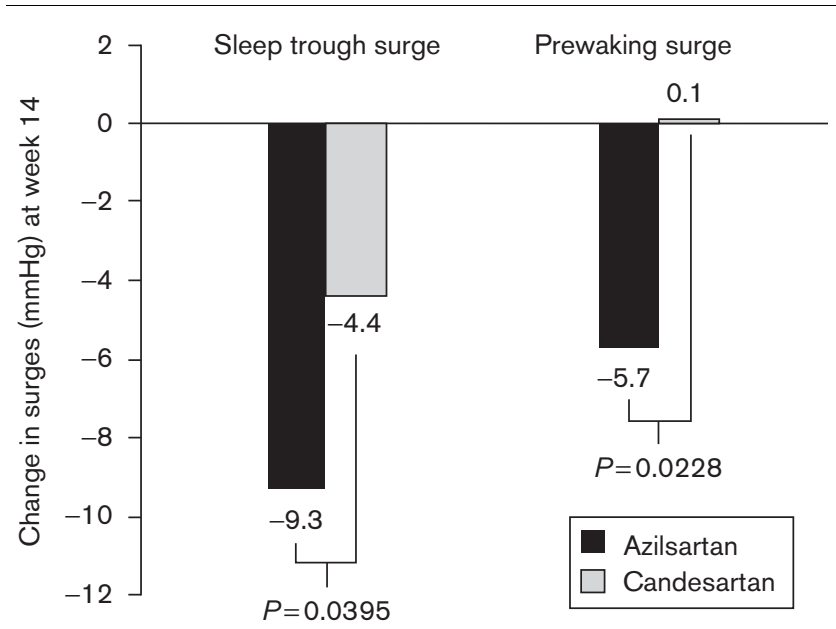

Changes in sleep trough surge (mean early morning BP minus lowest night-time BP) and the prewaking surge (mean early morning BP minus BP before awakening) from baseline (week 0) to week 14 in patients receiving treatment with azilsartan $(n=76)$ and candesartan $(n=71)$ in the surge group. BP, blood pressure.

including the long-acting calcium channel blocker amlodipine, which has been shown to reduce early morning $\mathrm{BP}$ in comparison with night-time BP and to control sleep trough surges by exerting an antihypertensive effect that corresponds to the BP level [25]. Among the ARBs, once- daily administration of candesartan has been reported to regulate sleep trough surges more potently than the ACE inhibitor lisinopril [26]. In the present analysis, we compared the efficacy of azilsartan on morning BP surges with that of candesartan by analyzing ABPM data according to the presence or absence of sleep trough surge in a previously reported randomized, double-blind study of the two ARBs in Japanese patients with stage I-II essential hypertension [23]. The key findings of the study were that in patients with sleep trough surge at baseline, administration of azilsartan decreased the lowest night-time SBP, the early morning SBP, and the SBP before awakening to a significantly greater extent than candesartan. As a result of the marked reduction in early morning SBP, both the sleep trough surge and the prewaking surge in these patients were significantly reduced by azilsartan in comparison with candesartan (least square means of the between-treatment differences -5.8 , 95\% CI $-11.34,-0.28 \mathrm{mmHg}, P=0.0395$; and $-5.7,95 \%$ CI $-10.68,-0.81 \mathrm{mmHg}, P=0.0228$, respectively).

In patients without a sleep trough surge at baseline (nonsurge group), the magnitude of changes in sleep trough surges and prewaking surges was mildly increased in both treatment groups (Table 2). Azilsartan and candesartan considerably reduced night-time mean SBP and lowest night-time SBP from baseline; therefore, both drugs increased the absolute values of surges. However, in the nonsurge group, both drugs also reduced early 
morning SBP at week 14 from baseline $(-8.7 \mathrm{mmHg})$, which was relatively lower at baseline. In other words, in the nonsurge group, both drugs increased the absolute values of surges, but with the positive potential that enables them to control and maintain SBPs lower from night-time to early morning. Thereby, these mild increased surges in the nonsurge group were not considered to be clinically meaningful.

The effects of antihypertensive agents on morning BP surges vary according to their mechanisms of action and the duration of their effects [27]. Early-morning enhancement of the renin-angiotensin system (RAS), endothelial functional disorder, and progression of vascular remodeling are considered to be involved in the enhancement of morning BP surges [28]. As RAS inhibitors are expected to have a morning BP surgeregulating action, by controlling the early morning enhancement of RAS, they may also improve small vessel remodeling, thereby stabilizing early morning $\mathrm{BP}$ in the long term [29].

Several clinical studies have shown that the effects of RAS inhibitors on morning BP surges vary from one drug to another. Whereas once-daily administration of candesartan has been shown to have a potent effect in regulating sleep trough BP surges [26], valsartan had no effect in regulating sleep trough surges [25]. This difference is believed to be related to the duration of the antihypertensive effect of these ARBs.

In an earlier in-vitro study, azilsartan was shown to have a more potent inhibitory effect on $\mathrm{AT}_{1}$ receptors and to dissociate more slowly from the receptor than other ARBs [22]. In the randomized, double-blind comparative study in Japanese patients with stage I-II essential hypertension from which ABPM data for the present study were derived, once-daily administration of azilsartan exerted a more potent and sustained 24-h BP-lowering effect than candesartan [23]. Therefore, the effect of azilsartan on morning BP surges may be related to its sustained action on the $\mathrm{AT}_{1}$ receptor.

Limitations of this study include the fact that several different definitions have been applied in studies of morning BP surges carried out to date. Although there is consensus that morning BP surges are associated with cardiovascular events, no consensus on their precise definition has been reached as yet [30]. In this analysis, the lowest night-time SBP, the early morning SBP, the SBP before awakening, the sleep trough surge, and the prewaking surge were defined as mentioned above (see the Methods section) using the study of Kario et al. [10] as a reference. In addition, the occurrence of a sleep trough BP surge was defined as an increase of SBP from the lowest night-time SBP to the mean early morning SBP of at least $35 \mathrm{mmHg}$ by reference to the definition in the IDACO study, which is the largest study of the correlation between morning BP surges and cardiovascular events published to date (IDACO used the definition of at least $37 \mathrm{mmHg}$ ) [20]. However, in the study of Kario and colleagues, an increase in SBP of at least $55 \mathrm{mmHg}$ from the lowest sleep level to the early morning level was applied to examine the prognostic implications of morning BP surges for silent and clinical cerebrovascular disease in elderly hypertensive patients; this higher morning BP surge was associated with a higher risk of stroke than lower morning SBP surges (less than $55 \mathrm{mmHg}$ ) [10]. A further limitation of the present study relates to the reproducibility of morning BP surges measured by conventional ABPM. This is because the time at which surges arise cannot be determined accurately and the extent of the surge is influenced by day-to-day variability of physical activity [30]. Because arising and ambulating from supine sleep is the major determinant of morning BP surges, BP may show little change if the patient remains supine after awakening [30]. Also, this study was a short-term evaluation, and did not evaluate the efficacy of the study medication in reducing cardiovascular events. The dosage selection of candesartan in this study should also be considered as another limitation. The rationale for increasing candesartan up to $12 \mathrm{mg}$ daily is that, in Japan, the approved maximum daily dosage of candesartan is $12 \mathrm{mg}$. The antihypertensive efficacy of candesartan $12 \mathrm{mg}$, telmisartan $80 \mathrm{mg}$, valsar$\tan 160 \mathrm{mg}$, and olmesartan $40 \mathrm{mg}$ has been shown to be equivalent to that of enalapril $20 \mathrm{mg}$ in Japanese patients with hypertension [31-34]. Therefore, further evaluations using large-scale databases are needed to determine the threshold morning BP surge level associated with an increased cardiovascular risk.

Although no study has scientifically shown that selective regulation of morning BP surges will limit the onset of cardiovascular events and target organ damage, it is clear that a sustained morning BP surge is a risk factor for cardiovascular events and organ damage independent of the 24-h BP level [10-19]. The current study has shown that azilsartan exerts a more pronounced effect in suppressing morning BP surges than candesartan. Thus, in addition to its potent and sustained antihypertensive effect, azilsartan may be expected to control morning BP surges and thereby help prevent the onset of cardiovascular events.

\section{Acknowledgements}

The authors thank all the patients, physicians, and medical staff who supported this study, and Content Ed Net for editorial assistance with the manuscript, which was funded by Takeda Pharmaceutical Company Limited.

\section{Conflicts of interest}

H.R. and K.K. served as medical experts for this study. H.R. received honoraria from Takeda Pharmaceutical Company for lectures he gave during the study period. 
K.E., K.S., and Y.I. are all employees of Takeda Pharmaceutical Company.

\section{References}

1 Willich SN, Levy D, Rocco MB, Tofler GH, Stone PH, Muller JE. Circadian variation in the incidence of sudden cardiac death in the Framingham Heart Study population. Am J Cardiol 1987; 60:801-806.

2 Muller JE, Stone PH, Turi ZG, Rutherford JD, Czeisler CA, Parker C, et al. Circadian variation in the frequency of onset of acute myocardial infarction. N Engl J Med 1985; 313:1315-1322.

3 Muller JE, Ludmer PL, Willich SN, Tofler GH, Aylmer G, Klangos I, et al. Circadian variation in the frequency of sudden cardiac death. Circulation 1987; 75:131-138

4 Maron BJ, Kogan J, Proschan MA, Hecht GM, Roberts WC. Circadian variability in the occurrence of sudden cardiac death in patients with hypertrophic cardiomyopathy. J Am Coll Cardiol 1994; 23:1405-1409.

5 Willich SN, Goldberg RJ, Maclure M, Perriello L, Muller JE. Increased onset of sudden cardiac death in the first three hours after awakening. Am J Cardiol 1992; 70:65-68.

6 Muller JE, Tofler GH, Stone PH. Circadian variation and triggers of onset of acute cardiovascular disease. Circulation 1989; 79:733-743.

7 Asayama K, Ohkubo T, Kikuya M, Obara T, Metoki H, Inoue R, et al. Prediction of stroke by home 'morning' versus 'evening' blood pressure values: the Ohasama study. Hypertension 2006; 48:737-743.

8 Miura K, Nakagawa H, Tabata M, Morikawa Y, Nishijo M, Kagamimori S. Birth weight, childhood growth, and cardiovascular disease risk factors in Japanese aged 20 years. Am J Epidemiol 2001; 153:783-789.

9 Kario K. Time for focus on morning hypertension: pitfall of current antihypertensive medication. Am J Hypertens 2005; 18:149-151.

10 Kario K, Pickering TG, Umeda Y, Hoshide S, Hoshide Y, Morinari M, et al. Morning surge in blood pressure as a predictor of silent and clinical cerebrovascular disease in elderly hypertensives: a prospective study. Circulation 2003; 107:1401-1406.

11 Gosse P, Lasserre R, Minifie C, Lemetayer P, Clementy J. Blood pressure surge on rising. J Hypertens 2004; 22:1113-1118.

12 Metoki H, Ohkubo T, Kikuya M, Asayama K, Obara T, Hashimoto J, et al. Prognostic significance for stroke of a morning pressor surge and a nocturnal blood pressure decline: the Ohasama study. Hypertension 2006; 47:149-154.

13 Kuwajima I, Mitani K, Miyao M, Suzuki Y, Kuramoto K, Ozawa T. Cardiac implications of the morning surge in blood pressure in elderly hypertensive patients: relation to arising time. Am J Hypertens 1995; 8:29-33.

14 Kario K, Pickering TG, Hoshide S, Eguchi K, Ishikawa J, Morinari M, et al. Morning blood pressure surge and hypertensive cerebrovascular disease: role of the alpha adrenergic sympathetic nervous system. Am J Hypertens 2004; 17:668-675.

15 Kaneda R, Kario K, Hoshide S, Umeda Y, Hoshide Y, Shimada K. Morning blood pressure hyper-reactivity is an independent predictor for hypertensive cardiac hypertrophy in a community-dwelling population. Am J Hypertens $2005 ; \mathbf{1 8 : 1 5 2 8 - 1 5 3 3 . ~}$

16 Polónia J, Amado P, Barbosa L, Nazaré J, Silva JA, Bertoquini S, et al. Morning rise, morning surge and daytime variability of blood pressure and cardiovascular target organ damage. A cross-sectional study in 743 subjects. Rev Port Cardiol 2005; 24:65-78.

17 Zakopoulos NA, Tsivgoulis G, Barlas G, Papamichael C, Spengos K, Manios E, et al. Time rate of blood pressure variation is associated with increased common carotid artery intima-media thickness. Hypertension 2005; 45:505-512.

18 Marfella R, Siniscalchi M, Portoghese M, Di Filippo C, Ferraraccio F, Schiattarella C, et al. Morning blood pressure surge as a destabilizing factor of atherosclerotic plaque: role of ubiquitin-proteasome activity. Hypertension 2007; 49:784-791.

19 Kario K. Vascular damage in exaggerated morning surge in blood pressure. Hypertension 2007; 49:771-772.

20 Li Y, Thijs L, Hansen TW, Kikuya M, Boggia J, Richart T, et al. Prognostic value of the morning blood pressure surge in 5645 subjects from 8 populations. Hypertension 2010; 55:1040-1048.

21 Kario K, Ishikawa J, Pickering TG, Hoshide S, Eguchi K, Morinari M, et al. Morning hypertension: the strongest independent risk factor for stroke in elderly hypertensive patients. Hypertens Res 2006; 29:581-587.

22 Ojima $\mathrm{M}$, Igata $\mathrm{H}$, Tanaka $\mathrm{M}$, Sakamoto $\mathrm{H}$, Kuroita $\mathrm{T}$, Kohara $\mathrm{Y}$, et al. In vitro antagonistic properties of a new angiotensin type 1 receptor blocker, azilsartan, in receptor binding and function studies. J Pharmacol Exp Ther 2011; 336:801-808.

23 Rakugi $\mathrm{H}$, Enya K, Sugiura K, Ikeda Y. Comparison of the efficacy and safety of azilsartan with that of candesartan cilexetil in Japanese patients with grade I-II essential hypertension: a randomized, double-blind clinical study. Hypertens Res 2012; 35:552-558.

24 Rakugi $\mathrm{H}$, Kario $\mathrm{K}$, Enya $\mathrm{K}$, lgeta $\mathrm{M}$, lkeda $\mathrm{Y}$. Effect of azilsartan versus candesartan on nocturnal blood pressure variation in Japanese patients with essential hypertension. Blood Press 2013; 22 (Suppl 1):22-28.

25 Eguchi K, Kario K, Hoshide Y, Hoshide S, Ishikawa J, Morinari M, et al. Comparison of valsartan and amlodipine on ambulatory and morning blood pressure in hypertensive patients. Am J Hypertens 2004; 17:112-117.

26 Eguchi K, Kario K, Shimada K. Comparison of candesartan with lisinopril on ambulatory blood pressure and morning surge in patients with systemic hypertension. Am J Cardiol 2003; 92:621-624.

27 Kumagai Y. Strategies against high blood pressure in the early morning. Clin Exp Hypertens 2004; 26:107-118.

28 Kario K. Preceding linkage between a morning surge in blood pressure and small artery remodeling: an indicator of prehypertension? J Hypertens 2007; 25:1573-1575.

29 Yano Y, Hoshide S, Inokuchi T, Kanemaru Y, Shimada K, Kario K. Association between morning blood pressure surge and cardiovascular remodeling in treated elderly hypertensive subjects. Am J Hypertens 2009; 22: 1177-1182.

30 Kario K. Morning surge in blood pressure and cardiovascular risk: evidence and perspectives. Hypertension 2010; 56:765-773.

31 Arakawa K, Shimamoto K, Abe K, Saruta T, Ishii M, Ogihara T, et al. Parallelgroup controlled clinical study on CS-866 (olmesartan medoxomil), a novel angiotensin II AT1 receptor antagonist, compared with enalapril maleate in patients with mild-to-moderate essential hypertension [in Japanese]. J Clin Ther Med 2004; 20:115-159.

32 Arakawa $\mathrm{K}$, Ogihara $\mathrm{T}$, limura $\mathrm{O}, \mathrm{Abe} \mathrm{K}$, Saruta $\mathrm{T}$, Ishii $\mathrm{M}$, et al. Evaluation of clinical usefulness of TCV-116 (candesartan cilexetil) in patients with essential hypertension: a double-blind, parallel-group comparison study using enalapril maleate as control drug [in Japanese]. J Clin Ther Med 1998; 14:871-918.

33 Yoshinaga K, limura O, Abe K, Saruta T, Arakawa M, Yazaki Y, et al. Clinical evaluation of CGP 48933 (valsartan) monotherapy in essential hypertension: double-blind comparative study with enalapril maleate [in Japanese]. J Clin Ther Med 1998; 14:2355-2404.

34 Arakawa K, Abe K, Saruta T, Yazaki Y, Ishii M, Ogihara T, et al. A double-blind comparison of efficacy and safety of BIBR277 (telmisartan), the long-acting angiotensin II AT1 receptor antagonist, and enalapril maleate in patients with mild-to-moderate essential hypertension: a multicenter, randomized, parallel-group comparison study [in Japanese]. Jpn Pharmacol Ther 2002; 30:639-660. 